\title{
A Psychometric Investigation of the Survey of Study Habits and Attitudes
}

\author{
James H. Bray \\ University of Houston \\ Scott E. Maxwell \\ University of Houston \\ Ronald R. Schmeck
Southern Illinois University
}

The present study investigated the reliability of the previously hypothesized four-factor model of the Survey of Study Habits and Attitudes (SSHA; Brown \& Holtzman, 1953, 1967). The reliabilities of the scales were marginal as measured by coefficient alpha. The hierarchical model of the SSHA was not supported by confirmatory factor analysis. Numerous test items were found to load highest on a factor other than the one hypothesized by the Brown-Holtzman model. In addition, many items exhibited very low communalities and failed to load highly on any factor.

The current literature in the field of human learning and memory suggests that Cronbach's (1957) call for less separation between differential and experimental research has finally had an impact on the human learning and memory areas. This impact is evidenced in part by the search for interactions between classical personality and memory measures (e.g., Eysenck, 1977; Mueller, 1979). It is also evidenced by attempts to develop measures of learning and memory abilities based, in part, on learning and memory research (e.g., Hunt, Frost, \& Lunneborg, 1973; Sternberg, 1979; cf. Carroll \& Maxwell, 1979). In accordance with Underwood's (1975) suggestion, this trend is also demonstrated by the development of process-oriented self-report inven-

APPLIED PSYCHOLOGICAL MEASUREMENT Vol. 4. No. 2 Spring 1980 pp. 195-201

(C) Copyright 1980 West Publishing Co. tories that assess individual differences on dimensions specifically suggested by research concerning memory processes (e.g., Schmeck, Ribich, \& Ramanaiah, 1977).

Modern self-report instruments have been developed for laboratory use (Schmeck et al., 1977), for the training setting (Kolb, 1974), and for the academic setting (Biggs, 1970; cf. Ribich \& Schmeck, in press). However, in terms of frequency of use, the most prevalently employed instrument assessing differences in behaviors related to learning and memory remains one that was originally developed prior to most modern information processing and memory research and prior to the development of much modern test construction technology. This instrument is the Survey of Study Habits and Attitudes (SSHA; Brown \& Holtzman, 1953, 1967).

The SSHA was originally designed to provide a single score that assessed effectiveness in academic settings (Brown \& Holtzman, 1953). However, in order to improve the instrument's usefulness in clinical settings, the items of the SSHA were subsequently revised and intuitively grouped to yield seven different scale scores (Brown \& Holtzman, 1967). The four basic scores are Delay Avoidance (DA), Work Methods (WM), Teacher Approval (TA), and Education Acceptance (EA). These scores are then combined to yield two second-order scores: Study Habits $(\mathrm{SH}=\mathrm{DA}+\mathrm{WM})$ and Study At- 
titudes ( $\mathrm{SA}=\mathrm{TA}+\mathrm{EA})$. And finally, the two second-order scales are combined to yield an overall score for Study Orientation ( $\mathrm{SO}=\mathrm{SH}+\mathrm{SA})$.

There is evidence (e.g., Brown \& Holtzman, 1967) that the overall SO score is a valid predictor of grade-point average; however, the literature contains little evidence concerning the independence, internal consistency, or discriminant validity of the individual scale scores. Goldfried and D'Zurilla (1973) reported that SO scores were more highly related to peer ratings of study effectiveness than to peer ratings of interpersonal effectiveness. They also reported that SH scores were slightly more related to peer ratings of study effectiveness than were SA scores. Although these results provide some evidence of discriminant validity, it should be noted that the same study showed the correlations between grade-point average and $\mathrm{SH}, \mathrm{SA}$, and $\mathrm{SO}$ to be $.16,-.15$, and .07 , respectively. Likewise, the intercorrelations among the four SSHA scales reported by Brown and Holtzman (1967) are quite high (ranging from .51 to .75), as are those reported by Robyak and Patton (1977), ranging from .41 to .75 .

To date, the only factor analysis of the SSHA known to the present authors is one that included the 18 scales of the California Psychological Inventory (CPI) in the analysis along with the four SSHA scales (Rutkowski \& Domino, 1975). Although the SSHA scales loaded slightly on other factors, their major loadings were on a single factor made up solely of all of the SSHA scales. Also, the intercorrelations among the CPI and SSHA scales suggest that in most cases when one SSHA scale related to a CPI scale, either most or all of the four SSHA scales related to the same CPI scale. Thus, the division of the SSHA items into four separate scales might be questioned.

The purpose of the present study was to investigate the psychometric properties of the SSHA scales. Because the SSHA is so widely used, both as a research tool and for academic counseling, it is important to determine the reliability of the scale scores. In addition, the underlying hierar- chical model proposed by Brown and Holtzman (1967) was tested using confirmatory factor analysis (Jöreskog, 1978).

\section{Method}

\section{Subjects}

Subjects were 1,899 undergraduate students at a large southwestern university. The students participated in the study as part of the regular requirements of a course on reading and study skills. The data employed presently represent archival SSHA scores from all students taking the course between 1974 and 1977. The SSHA was, in all cases, administered during the first week of the course.

\section{Instrument}

The SSHA is a 100 -item questionnaire designed to measure a student's study methods, motivation for studying, and attitudes toward academic activities. Students respond to each question using a 5-point scale $(1=$ Rarely to $5=$ Almost Always) that indicates the percentage of time they engage in an activity or agree with an item. A more detailed description of the SSHA can be found in Brown and Holtzman (1967).

\section{Analysis}

Reliability coefficients and confirmatory factor analysis techniques (COFAMM; Sörbom \& Jöreskog, 1976) were employed to investigate the psychometric properties of the SSHA. The underlying model proposed by Brown and Holtzman (1967) was tested using confirmatory factor analysis (Jöreskog, 1978). Prior to the factor analyses two statistical tests were conducted on the correlation matrix to determine whether the matrix was appropriate for factor analysis (Dziuban \& Shirkey, 1974). 


\section{Results}

\section{Scale Reliabilities}

Coefficient alpha values were calculated for each of the four basic subscales. Table 1 presents the reliability coefficients for each of the subscales. In general, the four scales have low reliabilities. Although the reliabilities for the WM and TA scales fall within the acceptable range for group research, none of the scales have reliabilities generally considered acceptable for individual counseling (Seibel, 1968). Items 6, 8, and 17 on scale DA; Item 2 on the TA scale; and Item 5 on the EA scale all have corrected itemtotal correlations that are not significantly different from zero $(p<.05)$ with their respective subscales.

The reliability coefficients for the two secondorder subscales are more acceptable (see Table 1). In particular, the reliability for the $\mathrm{SH}$ scale is within the acceptable range for group and individual purposes, whereas the reliability of the SA scale is acceptable for group use.

\section{Confirmatory Factor Analysis}

The overall measure of sampling adequacy (MSA; Kaiser, 1970) for the SO scale fell within the excellent range, MSA $=.95$. The MSAs for the individual items of the scale ranged from .80 to .97 , all in the excellent range. Bartlett's (1950) test for sphericity also indicated that the correlation matrix was appropriate for factor analy- sis, $\chi^{2}(4950)=51,277.099, p<.01$. It should be noted that both the MSA and Bartlett's test are sample-size dependent. Although the 100 SSHA items adequately represent the universe of possible items, these tests say nothing about the quality of the individual items (Dziuban \& Shirkey, 1974). In particular, the tests provided no information concerning the appropriateness of the item groupings that constitute the four hypothesized scales.

The Brown-Holtzman four-factor model was tested in the first step of the confirmatory factor analysis. The factor-loading matrix was constructed so that each individual item loaded only on the appropriate scale specified by Brown and Holtzman (1967). The correlations between the factors were allowed to vary freely, producing an oblique solution. The $\chi^{2}$ test of fit for the BrownHoltzman four-factor model, $\chi^{2}$ (4844) $=$ $20,171.717, p<.001$, indicated that this model provided a poor fit to the data. Two other indices of model fit were also calculated because the $\chi^{2}$ test is dependent on sample size (Schmitt, 1978). The $X^{2} / d f$ ratio equaled 4.16 for the model, and the Tucker-Lewis reliability coefficient (Tucker \& Lewis, 1973) was .662. These indices also substantiated the poor fit represented by the Brown-Holtzman four-factor model.

Because of the poor fit provided by the BrownHoltzman model, a more general model was proposed and tested. In this analysis a model with four factors was again specified, but each item could load freely on any factor. The maximum

Table 1

Reliability Coefficients for the 4 SSHA Subscales and 2 second Order Subscales

\begin{tabular}{ll}
\hline Subscale & Coefficient \\
\hline Delay Avoidance & .653 \\
Work Methods & .812 \\
Teacher Approval & .848 \\
Education Acceptance & .749 \\
Study Habits & .878 \\
Study Attitudes & .830 \\
\hline
\end{tabular}


likelihood solution for this model, $\chi^{2}(4556)=$ $12,777.88, p<.001$, was significantly better than the fit for the first model. The $\chi^{2} / d f$ ratio for this unrestricted model was 2.80 , with the TuckerLewis reliability equal to .807 . This model represented a considerably better fit but, overall, even this unrestricted model was still relatively poor.

Examination of the rotated factor loadings for the unrestricted four-factor model indicated that $\mathbf{1 9}$ of the items did not have a loading as large as .35 for any factor (Items $4,8,15,20,21$, $22,29,32,33,42,56,65,68,76,77,84,92,93$, and 99). In addition, many of the remaining items did not load on the factor specified by Brown and Holtzman (1967).

Examination of the item communalities for the unrestricted model indicated that they were low (mean communality=.367, $S D=.097$, range of .15 to .58 ). This finding suggests (1) the items had large error variance; (2) the items had large unique variance; or (3) the correlation matrix was underfactored. In fact, an exploratory factor analysis revealed that the correlation matrix had 20 eigenvalues greater than 1. However, even with 20 factors the communalities were still low (mean $=.368, S D=.105$ ). In any case, it appeared that the items share little variance among themselves.

The second stage of the Brown-Holtzman model was tested by conducting a second-order confirmatory factor analysis. The four basic subscales were hypothesized to have a factor structure such that the DA and WM subscales load on one factor (SH factor), and the TA and EA subscales load on a second factor (SA factor). Two approaches were used to test this secondorder model. The first approach utilized the intercorrelations among the four oblique factors that resulted from the first-order analysis (see Table 2). The $\chi^{2}$ test of fit for this second-order model, $\chi^{2}(1)=250.409, p<.001$, indicated that this model provided a poor fit. Inspection of the factor intercorrelations revealed that the DA and TA factors correlated higher (.81) than the DA and WM factors correlated (.62), contrary to what the model predicts.

The second approach utilized the intercorrelations among the four subscales constructed according to Brown and Holtzman (1967) by summing over the relevant items for each subscale (see Table 3). The $\chi^{2}$ test of fit for the same second-order model, $\chi^{2}(1)=2.633, p<.105$, indicated that this model provides a good fit for this correlation matrix.

\section{Discussion}

The results of this study have important implications for both substantive and methodological considerations. The confirmatory factor analyses based on item intercorrelations did not support the Brown-Holtzman model. However, when analyses were based on subscale intercorrelations, the results seemed to be discrepant. The discrepancy may be due to (1) the effect of unit versus empirical weighting; (2) the variables

$$
\text { Table } 2
$$

Intercorrelations of the Brown-Holtzman 4 Basic Subscales Determined Through Confirmatory Factor Analysis

\begin{tabular}{lrrr}
\hline Scale & DA & WM & TA \\
\hline Delay Avoidance & 1.000 & & \\
Work Methods & .619 & 1.000 & \\
Teacher Approval & .433 & .513 & 1.000 \\
Education & .806 & .556 & .736 \\
Acceptance & & & \\
\hline
\end{tabular}




\section{Table 3}

Intercorrelations of the Brown-Holtzman 4 Basic Subscales Determined by Summing Across Items

\begin{tabular}{lrrr}
\hline Scale & DA & WM & TA \\
\hline Delay Avoidance & 1.000 & & \\
Work Methods & .413 & 1.000 & 1.000 \\
Teacher Approval & .107 & .176 & .414 \\
Education & .203 & .244 & \\
Acceptance & & & \\
\hline
\end{tabular}

correlated in Table 2 represent latent constructs, whereas those in Table 3 are fallible; and/or (3) the factors in Table 2, unlike those in Table 3, are sensitive to correlations among individual items both between and within subscales.

This apparent contradiction is further evidence of the complexity of each of the four basic subscales. As Mulaik (1972) states, there "is a danger in using composite scores to study the complexity of a phenomenon. The composite scores will obscure any potential complexity that exists within the composites; as a result one may have the tendency in theoretical discussions to treat the composite as a homogeneous entity" ( $p$. 69). Thus, interpretation of the four subscales and higher-order scales is problematic, given the complexity found in the subscales. Consequently, this empirical approach generally does not support the validity of the intuitive approach used in constructing the scales.

The reliabilities for the four subscales were below the standards (Seibel, 1968) for use in individual situations. This finding is in contrast to the reliabilities reported by Brown and Holtzman (1967). In their reliability studies, using a much smaller $N$ than in the present study, they found the reliability of the four subscales ranged from .87 to .93 . Other than differences in sample size, it is not clear why there is such a discrepancy between Brown and Holtzman's findings and those in the present study. It should be noted that the DA scale in the present study had unacceptable reliability, even for group re- search. Because these scales are so widely used in both research and counseling, these findings should serve as a warning to workers who employ the SSHA, particularly for individual counseling.

The increase in internal consistency reliability for the second-order scales is both good and bad. Some increase in reliability would be expected simply because of the increase in the number of items. However, the large increase in reliability from the DA and WM subscales to the second-order $\mathrm{SH}$ scale suggests that these are not really two different subscales. This finding is also substantiated by the confirmatory factor analysis. Thus, the first-order scales have questionable reliability and meaning. In contrast, the second-order scales are reliable measures, but it is not clear what they measure.

It should be noted that although the present study provides data concerning the independence and internal consistency of the SSHA scales, it provides no direct evidence concerning discriminant validity. However, a search for validity in the absence of reliability would seem to be a futile exercise. The present authors are also troubled by the fact that the SSHA item pool evidences little influence from modern information processing and memory research. Brown and Holtzman (1967) noted that other than a few minor changes in wording, "the research instrument employed in all investigations at the college level since 1956 has been, essentially, the 100 -item SSHA resulting from the 1956 revi- 
sion" (p. 26). Unfortunately, the "cognitive revolution" in psychology has occurred since 1956, and the fields of learning and memory have changed drastically. The attention of counselors is drawn to the Study Behavior Questionnaire (Biggs, 1970), and researchers might consider using the Inventory of Learning Processes (Schmeck et al., 1977). These instruments have better psychometric properties than the SSHA, and both sample a content domain that includes the variables deemed to be important by modern information processing and memory researchers.

\section{References}

Bartlett, M. S. Tests of significance in factor analysis. British Journal of Psychology, 1950, 3, 77-85.

Biggs, J. B. Faculty patterns in study behavior. Aus tralian Journal of Psychology, 1970, 22, 161-174.

Brown, W. F., \& Holtzman, W. H. Survey of study habits and attitudes. New York: The Psychological Corporation, 1953.

Brown, W. F., \& Holtzman, W. H. Survey of study habits and attitudes. New York: The Psychological Corporation, 1967.

Carroll, J. B., \& Maxwell, S. E. Individual differences in cognitive abilities. Annual Review of Psychology, 1979, 30, 603-640.

Cronbach, L. J. The two disciplines of scientific psychology. American Psychologist, 1957, 12, 671-684.

Dziuban, C. D., \& Shirkey, E. C. When is a correlation matrix appropriate for factor analysis?: Some decision rules. Psychological Bulletin, 1974, 81, 358-361.

Eysenck, M. W. Human memory: Theory, research, and individual differences. New York: Pergamon Press, 1977.

Goldfried, M. R. \& D'Zurilla, T. J. Prediction of academic competence by means of the Survey of Study Habits and Attitudes, Journal of Educational Psychology, 1973, 64, 116-122.

Hunt, E., Frost, N., \& Lunneborg, C. Individual differences in cognition: A new approach to intelligence. In G. Bower (Ed.), The psychology of learning and motivation (Vol. 7). New York: Academic Press, 1973.
Jöreskog, K. G. Structural analysis of covariance and correlation matrices. Psychometrika, 1978, 43, 443-477.

Kaiser, H. F. A second generation little jiffy. Psychometrika, 1970, 35, 401-416.

Kolb, D. A. On management and the learning process. In D. A. Kolb, I. M. Rubin, \& J. M. McIntyre (Eds.), Organizational psychology: $A$ book of readings. Englewood Cliffs, NJ: PrenticeHall, 1974.

Mueller, J. H. Test anxiety and the encoding and retrieval of information. In I. G. Sarason (Ed.), Test anxiety: Theory, research, and applications. Hillsdale, NJ: Erlbaum, 1979.

Mulaik, S. A. The foundations of factor analysis. New York: McGraw-Hill, 1972.

Ribich, F. D., \& Schmeck, R. R. Multivariate relationships between measures of learning style and memory. Journal of Research in Personality, in press.

Robyak, J. E., \& Patton, M. J. The effectiveness of a study skills course for students of different personality types. Journal of Counseling Psychology, 1977, 24, 200-207.

Rutkowski, K., \& Domino, G. Interrelationship of study skills and personality variables in college students. Journal of Educational Psychology. 1975, 67, 784-789.

Schmeck, R. R., Ribich, F., \& Ramanaiah, N. Development of a self-report inventory for assessing individual differences in learning processes. Applied Psychological Measurement, 1977, 1, 413-431.

Schmitt, N. Path analysis of multitrait-multimethod matrices. Applied Psychological Measurement, 1978, 2, 157-173.

Seibel, D. W. Measurement of aptitude and achievement. In D. K. Whitla (Ed.), Handbook of measurement and assessment in behavioral sciences. Reading, MA.: Addison-Wesley, 1968.

Sörbom, D., \& Jöreskog, K. G. Confirmatory factor analysis with model modification manual. Chicago, IL: National Educational Resources, Inc., 1976.

Sternberg, R. J. The nature of mental abilities. American Psychologist, 1979, 34, 214-229.

Tucker, L. R., \& Lewis, C. A reliability coefficient for maximum likelihood factor analysis. Psychometrika. 1973, 38, 1-10.

Underwood, B. J. Individual differences as a crucible in theory construction. American Psycholegist, $1975,30,128-134$. 


\section{Acknowledgments}

We would like to express our appreciation to Eugene B. Doughtie for providing the archival data from his classes that was used in this study. Authorship is listed alphabetically as each author contributed equally.

\section{Author's Address}

Send requests for reprints or further information to Scott E. Maxwell, Department of Psychology, University of Houston, Houston, TX 77004. 